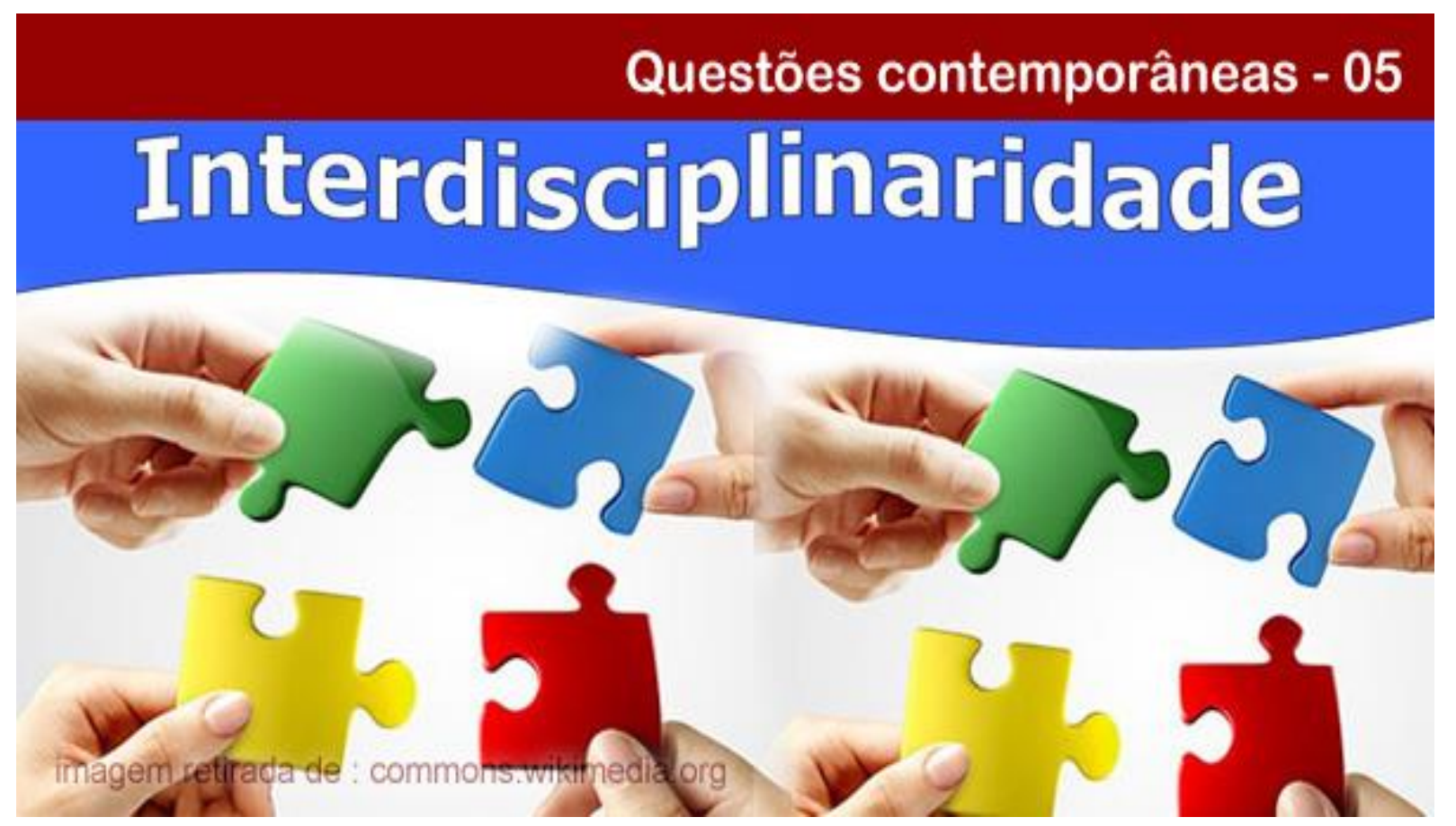

\title{
INTERDISCIPLINARIDADE E OUTROS NÍVEIS DE CONHECIMENTO: DESAFIOS CONTEMPORÂNEOS ÀS PRÁTICAS EDUCATIVAS
}

\author{
Antônio Roberto Xavier \\ Professor Permanente do Mestrado em Sociobiodiversidade e Tecnologias Sustentáveis e do Curso de \\ Graduação em Administração Pública, ambos da Universidade da Integração Internacional da Lusofonia Afro- \\ Brasileira (UNILAB). Pós-doutor em Educação pela Universidade Federal da Paraíba (UFPB). Doutor em \\ Educação pela Universidade Federal do Ceará(UFC). E-mail: roberto@ unilab.edu.br.
}

\section{José Gerardo Vasconcelos}

Professor Titular de Filosofia de Graduação e Pós-graduação stricto sensu da Universidade Federal do Ceará (UFC). Pós-doutor em Educação pela Universidade Federal da Paraíba (UFPB). Doutor em Sociologia pela Universidade Federal do Ceará (UFC). E-mail: gerardovasconcelos1964@gmail.com.

\section{Maria Jucilene Freire Lopes Marinho}

Professora da Secretaria Estadual da Educação do Ceará (SEDUC-CE). Mestra em Informática Educativa (Computação Aplicada) pela Universidade Estadual do Ceará (UECE).E-mail: jucilnef@ gmail.com.

\section{Ana Paula Sthel Caiado}

Professora Adjunta da Universidade da Integração Internacional da Lusofonia Afro-Brasileira (UNILAB). Doutora em Psicologia Escolar e Desenvolvimento Humano pela Universidade de São Paulo (USP). E-mail: apcaiado@unilab.edu.br.

Resumo: Este artigo objetiva, sobretudo, promover o debate teórico-epistemológico sobre os desafios e possibilidades do desenvolvimento de ensino-aprendizagem interdisciplinar em razão das matrizes curriculares adotadas. É fato que a discussão sobre interdisciplinaridade no trabalho docente, apesar de não ser tão nova, encontra-se em alta e mantém interfaces com outras categorias do gênero, principalmente quando se relaciona com a gestão e as práticas educativas em sala de aula. Nesse sentido, para a produção deste artigo, seguiram-se os caminhos metodológicos da pesquisa bibliográfica do tipo descritiva com base em revisão de literatura de fontes secundárias de livros, artigos, legislação e documentos oficiais. No tocante à abordagem, acolheu-se a

\section{POLÊM!CA LABORE (3)}

Polêmica - Revista Eletrônica da Uerj - Rua São Francisco Xavier, 524, $1^{\circ}$ andar bloco D, sl.1001 • Tels.: +55 21 2334-4088/4087 • http://www.e-publicacoes.uerj.br/index.php/polemica/index http://www.labore.uerj.br • laboreuerj@yahoo.com.br 
qualitativa, visando análise mais aprofundada das categorias elencadas, a saber: interdisciplinaridade, etnociência, multidisciplinaridade, pluridisciplinaridade e transdisciplinaridade, destacadas nos respectivos tópicos deste artigo. Com relação à técnica interpretacional, recorreu-se à análise do discurso na perspectiva da relação indissociável do histórico com o social. Como conclusão sucinta, deixou-se posto que as práticas educativas de forma interdisciplinar são dinamizadoras e facilitadoras para uma compreensão mais ampla e diversa do ensino-aprendizagem. Desse modo, possibilitam a formulação de um saber crítico-reflexivo, promovendo a integração de conteúdos nas mais diversas áreas de conhecimento, incluindo, inclusive, o arcabouço cultural dos saberes populares e não formais aos formais e científicos.

Palavras-chave: Interdisciplinaridade. Etnociência. Multidisciplinaridade.

\title{
INTERDISCIPLINARITY AND OTHER LEVELS OF KNOWLEDGE: CONTEMPORARY CHALLENGES TO EDUCATIONAL PRACTICES
}

\begin{abstract}
This article aims, above all, to promote the theoretical-epistemological debate on the challenges and possibilities of the development of interdisciplinary teaching-learning due to the curricular matrices adopted. It is a fact that the discussion about interdisciplinarity in teaching work, although not so new, is up and maintains interfaces with other categories of the genre, especially when it is related to management and educational practices in the classroom. In this sense, for the production of this article, we followed the methodological paths of bibliographic research of the descriptive type based on literature review of secondary sources of books, articles, legislation and official documents. With regard to the approach, the qualitative approach was adopted, aiming at a more in-depth analysis of the categories listed, namely: interdisciplinarity, ethnoscience, multidisciplinarity, multidisciplinarity and transdisciplinarity, highlighted in the respective topics of this article. With regard to the interpretative technique, we used the analysis of discourse in the perspective of the inseparable relationship between historical and social. As a succinct conclusion, it is emphasized that interdisciplinary educational practices are dynamic and facilitating a broader and more diverse understanding of teaching and learning. In this way, its allows the formulation of a critical-reflexive knowledge, promoting the integration of contents in the most diverse areas of knowledge, including the cultural framework of popular and non-formal knowledge to formal and scientific knowledge.
\end{abstract}

Keywords: Interdisciplinarity. Ethnoscience. Multidisciplinarity.

\section{Introdução}

"O todo está na parte que está no todo"

(MORIN, 2007, p. 75).

A epígrafe de Morin (2007) leva a entender que uma parte não só está contida no todo, mas o representa em sua plenitude, pois esse todo está na parte, com a parte, para a parte e além da parte, transbordando suas teias de imbricamento, constituindo-se numa complexidade vívida de conhecimentos plurais sempre presentes nas práticas educativas que levam ao ensino-aprendizagem a perspectiva da interdisciplinaridade.

Sob esse viés, o vocábulo "interdisciplinaridade" tem se consolidado e preenchido espaços no âmbito acadêmico-científico e educacional nas últimas décadas, “em geral, [...] envolvendo disciplinas diversas no interior da escola, projetos ou programas de cunho social com caráter de extensão, muitas vezes tendo à frente instituições de ensino superior e/ou empresas" (SOUZA; MOREIRA; PEREIRA, 2017, p. 66).

\section{POLÊM!CA $\mid$ LABORE}

Polêmica - Revista Eletrônica da Uerj - Rua São Francisco Xavier, 524, $1^{\circ}$ andar

bloco D, sl.1001 • Tels.: +55 21 2334-4088/4087 • http://www.e-publicacoes.uerj.br/index.php/polemica/index

http://www.labore.uerj.br • laboreuerj@yahoo.com.br 
Nessa ótica, o presente artigo busca fomentar o debate sobre a interdisciplinaridade e outras categorias do conhecimento que se associam de uma forma ou de outra no acontecer do ensino-aprendizagem por meio de práticas educativas envolvendo as ciências formais, empírico-formais e hermenêuticas ${ }^{1}$.

A interdisciplinaridade se apresenta como alternativa possível e plausível para as diversas realidades educativas no atual estado de coisa. "Mas o que é realmente a interdisciplinaridade? Como passar das perspectivas teóricas à prática da colaboração interdisciplinar tanto no nível científico como educativo?" (ALBARRACIN; SILVA; SCHIRLO, 2013, p. 12).

Como possíveis e contextuais respostas às questões supracitadas, Souza, Moreira e Pereira (2017), com base em Fazenda (1993) e Freire (1987), declinam que:

No trabalho educativo, o que se designa por interdisciplinaridade é uma atitude
epistemológica que ultrapassa os hábitos intelectuais estabelecidos ou mesmo os
programas de ensino já consolidados [...], conduzem a perceber a
interdisciplinaridade como um processo metodológico na construção do
conhecimento pelo próprio sujeito a partir das interações socioculturais, num
movimento dialético entre uma situação que desvela a realidade de um lado, e, do
outro, a sistematização desses conhecimentos integradamente. (SOUZA,
MOREIRA; PEREIRA, 2017, p. 60).

Pelo visto, a discussão sobre interdisciplinaridade e outros níveis de conhecimento dela derivados, a exemplo da etnociêcia ${ }^{2}$, multidisciplinaridade, pluridisciplinaridade e transdisciplinaridade, encontra espaço fértil para discussões e reflexões amplas. Porém, apesar de "interdisciplinaridade" ser palavra de ordem não só no Brasil como também no mundo, esta tem permanecido apenas no discurso, haja vista que as práticas docentes esbarram, muitas vezes, nas barreiras dos currículos tradicionais, deixando os professores sem saber como inserir e o que fazer na prática com a proposta de uma educação inter e/ou transdisciplinar.

Nessa ótica, trabalhar conteúdos interdisciplinarmente não é a mesma coisa de se trabalhar disciplinas cada uma com sua metodologia própria e resultados não integrados, nas quais, embora haja uma temática comum, não existe ou não se trabalha visando identificar possíveis relações e cooperações entre as disciplinas. Isto é próprio da multidisciplinaridade. A interdisciplinaridade também não procura um único objeto de estudo em mais de uma

\footnotetext{
${ }^{1}$ Ciências formais: lógica e matemática; empírico-formais: biologia, física e química; e hermenêuticas: ciências humanas e suas subdivisões (MORAIS, 1988).

2 Etnociência refere-se ao campo multidisciplinar da antropologia que busca o desenvolvimento do conhecimento científico a partir do arcabouço cultural presente nos saberes tradicionais (TRUEBA, 2002).
}

\section{POLÊM!CA $\mid$ LABORE}


disciplina. Esta é tarefa da pluridisciplinaridade, que apesar de ter cooperação entre os conteúdos não apresenta sistematização ou troca de saberes de forma organizada. Com relação a transdisciplinaridade, essa é considerada etapa superior à interdisciplinaridade, haja vista atingir não apenas interações ou reciprocidades coordenadas entre os conteúdos trabalhados como faz o conhecimento interdisciplinar, mas proporciona interação global das várias ciências de maneira inovadora e inseparável (CARLOS, 2007; SANTOS; MENEZES, 2010; FAZENDA, 2010, 2011).

Metodologicamente, essa é uma pesquisa de abordagem teórica do tipo descritivointerpretativa. Quanto à abordagem, é prevalentemente qualitativa com fundamentação em fontes secundárias de livros, artigos e documentos oficiais. Nesse sentido, se alcança a geração de informações e ideias por meio de revisão de literatura. Com relação à técnica de análise, recorreu-se a interpretativa, em relação ao arcabouço bibliográfico utilizado.

Justificadamente, é possível se constatar a importância da discussão da categoria interdisciplinaridade com os outros níveis interativos do conhecimento na perspectiva das práticas educativas diante das matrizes curriculares. A interdisciplinaridade interage com as categorias de conhecimento supracitadas proporcionando, ainda mais, a formulação de um saber crítico-reflexivo, por promover a integração dos conteúdos das mais diversas áreas de conhecimento. Com efeito, a interdisciplinaridade junto à democracia pedagógica são tidas como metodologias facilitadoras para a compreensão da atual sociedade em constante estado de transformações e inovações educacionais (MORIN, 2008).

Não menos justificador é o consenso de que se vive numa sociedade plural e interconectada cujas relações de informação e comunicação ocorrem em tempo real e virtual em rede. Para atender às necessidades do conhecimento dessa sociedade, a interdisciplinaridade soa como prática educacional inovadora de transformação e mudanças sociais. Isso ocorre quando há sistematização de matérias ou disciplinas integradoras e imbricamento de conteúdos, métodos, teorias e empirias. A interdisciplinaridade é dinâmica e móvel, a qual só se aprende praticando e vivendo - ou sendo, pertencendo e fazendo. Desse modo, a multiplicidade de saberes acontece de forma célere e em teias relacionais. No universo do conhecimento, as linguagens educacionais não podem nem devem ser entendidas ou atribuídas isoladamente e/ou de forma estanque, mas interdisciplinarmente (FAZENDA, 2011; WERNECK, 1998).

\section{POLÊM!CA $\mid$ LABORE}


Nas práticas educativas, como educadores-educandos, tanto na educação básica quanto na educação universitária/superior, convive-se diariamente com esse processo de interdisciplinaridade e/ou transdisciplinaridade nas experiências relacionais direta e indiretamente, sobretudo no cenário atual da cibercultura e das práticas digitais, contexto que agrega, aproxima e compartilha conhecimentos múltiplos, criando interatividade entre as mais distantes e diferentes pessoas em e de todas as partes do planeta através da comunicação e informação virtuais (LÉVY, 1999).

Destarte, o presente artigo segue abordando de forma teórica e conceitual a interdisciplinaridade e suas interações com outros níveis de conhecimento com base em teóricos, tais como: Fazenda (1994, 2008, 2010, 2011); Japiassu (1976); Santos e Menezes (2010); Gamito (2013); Morais (1988); Morin (2007, 2008); Carlos (2007), e em documentos oficiais de governo como Leis e Diretrizes da educação nacional.

\section{Etnociência e interdisciplinaridade}

O termo "etnociência" tem na antropologia e na etnologia seus fundamentos epistemológicos. A etnociência viabiliza a compreensão das ações e produções materiais da pessoa humana em diferentes contextos, partindo dos saberes populares e/ou do conhecimento do senso comum e alcançando o conhecimento científico. Ao mesmo tempo, convida a reflexões e discussões fecundas e possíveis sobre a imaterialidade, oriundas das inúmeras simbologias e representações. Trata-se de uma palavra composta de "etno" mais "ciência", ou seja, o conhecimento científico a partir do compósito cultural formador das etnias; em síntese, representa "[...] toda e qualquer aplicação das disciplinas científicas ocidentais aos fenômenos naturais que são apreendidos de outra forma pelo pensamento nativo" (PANOFF; PERRIN, 1973, p. 78).

O significado de etnociência encontra-se em construção desde meados do século passado. Inicialmente o termo foi muito utilizado prefixalmente às ciências da natureza, como: etnobiologia, etnobotânica, etnozoologia, etnofísica, etnoquímica. Em seguida, foi aplicado nas linguagens, como etnolinguística e etnomatemática. Atualmente esse léxico é e pode ser empregado numa gama de etnoconhecimento e/ou etnossaberes (PANOFF; PERRIN, 1973).

\section{POLÊM!CA $\mid$ LABORE,}

Polêmica - Revista Eletrônica da Uerj - Rua São Francisco Xavier, 524, $1^{\circ}$ andar

bloco D, sl.1001 • Tels.: +55 21 2334-4088/4087 • http://www.e-publicacoes.uerj.br/index.php/polemica/index

http://www.labore.uerj.br • laboreuerj@yahoo.com.br 
A etnociência suscita a interdisciplinaridade das ações e produções do conhecimento em distintos contextos do fazer humano, fomentando simultaneamente reflexões e discussões fecundas sobre as subjetividades possíveis decorrentes das variadas simbologias e/ou representações dessas ações. Também permite identificar e incentivar a utilização de concepções, conteúdos, estratégias didáticas e metodológicas, visando ao desenvolvimento da pesquisa e do ensino-aprendizagem em todos os campos possíveis e plausíveis das ciências empírico-formal, formal e hermenêutica a partir da realidade (MORAIS, 1988).

As pesquisas e produções do conhecimento no campo das etnociências com as ciências hermenêuticas estão se alargando e ampliando seus horizontes em face das novas exigências de ordem científica, profissional, sociocultural, política e econômica no âmbito das ciências empírico-formal e formal, e não deveria ser diferente, sobretudo em razão das novas e aperfeiçoadas linguagens tecnológicas que, mutatis mutandis, se apresentam a cada dia (FERREIRA, 2014).

Desse modo, seguindo a tendência das inúmeras possibilidades do desenvolvimento das pesquisas e do ensino-aprendizagem, eis que surge nas últimas décadas a proposta de pesquisa e ensino no âmbito das etnociências. Estas se apresentam e se desnudam fertilmente como proposta didático-pedagógica e metodológica interdisciplinar, viabilizando pesquisas, estudos e compreensões de fenômenos científicos na seara das ciências da natureza e da matemática. As etnociências, por certo, não são nada mais do que a busca de conhecimento científico a partir dos saberes populares e das práticas cotidianas, muitas vezes, presentes em derredor da realidade observada. Esses saberes populares constituem a seiva das etnociências, haja vista que estas são constituídas pela construção da realidade do ser, do concreto, e não da abstração.

Em sua essência, as etnociências confrontam e contemplam o conhecimento acadêmico-científico com o conhecimento popular, estudando e aprendendo conhecimentos e conceitos desenvolvidos de uma cultura sobre diferentes e múltiplas áreas em que o prefixo "etno" faz referência a aspectos e conhecimentos específicos de povos, nações, coletividades, comunidades, aldeias e tribos que compartilham uma cultura.

As etnociências correspondem ao estudo de outras realidades de relações e interações do homem-natureza-homem através do tempo e dos processos culturais que os envolvem. Elas fundamentam-se na interdisciplinaridade das ações, perquirindo a importância do

\section{POLÊM!CA $\mid$ LABORE}


desenvolvimento intelectual dos etnossaberes/etnoconhecimentos e seu retorno de forma benéfica àquele que o tem gerado. Dessa forma, "etnociência" é uma palavra composta do prefixo "etno" seguido dos demais complementos que denominam os ramos do conhecimento, como: a (etno)matemática, a (etno)física, a (etno)química, a (etno)biologia, a (etno)história, a (etno)geografia, etc. (FERREIRA, 2014).

No contexto do ensino, pesquisa e extensão, a práxis das etnociências intensifica uma caminhada de expectativas, desafios e perspectivas no intuito de alcançar a diversidade de experiências e "diálogos interdisciplinares" entre o ensino de ciências e a educação com arrimo no arcabouço cultural de todos os seres humanos individual e coletivamente. Além disso, traz à tona oportunamente os cenários possíveis e plausíveis no campo da compreensão e do ensino-aprendizagem das ciências empírico-formais e da educação matemática mediante os recursos didático-metodológicos dos saberes populares.

\section{Interdisciplinaridade e outras interações do conhecimento}

Assim, os desenvolvimentos disciplinares das ciências trouxeram as vantagens da divisão do trabalho, mas também os inconvenientes da superespecialização, do confinamento e do despedaçamento do saber (MORIN, 2008, p. 15).

Ao falar-se de interdisciplinaridade, é racional ressaltar que há uma referência a algum tipo de interação entre as diversas áreas do conhecimento. Tornou-se um certo modismo no Brasil reportar-se à interdisciplinaridade quando o assunto é a gestão docente nas práticas educativas, especialmente com o advento da Constituição Federal de 1988 e da Lei n $^{\circ}$ 9.394/1996 (Lei de Diretrizes e Bases da Educação Nacional - LDBEN).

A abordagem simplista, didática, técnica e, às vezes, dicionarista demonstra que o vocábulo "interdisciplinar" (como adjetivo) é composto pelo prefixo "inter" acrescido da palavra "disciplinar". Nesse caso, o prefixo "inter" é a parte conectora, idealizando o que interliga, está entre, dentro ou em meio ao e com o "disciplinar". O vocábulo "disciplinar", por sua vez, significa seguir regras, preceitos, padrões, diretrizes, tino, etc., o qual, somado com o prefixo "inter", forma o substantivo "interdisciplinar", indicando as partes comuns ou as interligações entre as várias searas do conhecimento que podem e devem ser seguidas ou trabalhadas interativamente na busca de uma compreensão mais ampla, na qual seja possível perceber as interconexões pertinentes a um objeto de estudo com outros.

\section{POLÊM!CA $\mid$ LABORE}


Assim, interdisciplinaridade, no sentido etimológico/pedagógico, significa aquilo que é comum entre duas ou mais disciplinas nos mais diversos ramos do conhecimento. É ação recíproca do processo integrador presente referente às várias disciplinas estudadas e analisadas no campo do ensino-aprendizagem nas diversas áreas do conhecimento (CARLOS, 2007; FAZENDA, 1994, 2008; GAMITO, 2014; JAPIASSU, 1976).

Entretanto, o substantivo "interdisciplinaridade" é de caráter polissêmico. Por assim ser, existem, na busca de sua decifração epistemológica, algumas variantes de significados apontadas por Japiassu (1976) e interpretadas por Carlos (2007) em intenso estudo sobre interdisciplinaridade e seus tipos.

Destarte, Carlos (2007) aponta pelo menos cinco tipos de interdisciplinaridades: a interdisciplinaridade heterogênea, a pseudo-interdisciplinaridade, a interdisciplinaridade auxiliar, a interdisciplinaridade compósita e a interdisciplinaridade unificadora. O primeiro tipo "vem a ser uma espécie de enciclopedismo, baseado na 'soma' de informações procedentes de diversas disciplinas [...]", em que as " idéias [sic] gerais são geradoras de imobilismo" (CARLOS, 2007, p. 165). O segundo tipo vincula-se a “[...] diversas tentativas de utilização de certos instrumentos conceituais e de análise, considerados epistemologicamente 'neutros' [...], pode ser tachado de falso interdisciplinar" (CARLOS, 2007, p. 43). O terceiro tipo "[...] consiste [...] no fato de uma disciplina tomar de empréstimo a uma outra seu método ou seus procedimentos. Em alguns casos, este tipo de interdisciplinaridade não ultrapassa o domínio da ocasionalidade e das situações provisórias" (CARLOS, 2007, p. 43). O quarto tipo trata:

[...] de reunir várias especialidades para encontrar soluções técnicas tendo em vista resolver determinados problemas [...]. O que se verifica é apenas uma conjugação de disciplinas por aglomeração, cada uma dando sua contribuição, mas guardando a autonomia e a integridade de seus métodos, de seus conceitos-chave e de suas epistemologias (CARLOS, 2007, p. 44-45).

E o quinto tipo (o unificador):

Procede de uma coerência bastante estreita dos domínios de estudo das disciplinas, havendo certa integração de seus níveis de integração teórica e dos métodos correspondentes. Por exemplo, certos elementos e certas perspectivas da biologia ganharam o domínio da física para formar a biofísica (CARLOS, 2007, p. 45).

\section{POLÊM!CA $\mid$ LABORE}


Ainda segundo Carlos (2007, p. 44), esses tipos de interdisciplinaridade “[...] podem ser reduzidos a dois: a interdisciplinaridade linear (ou cruzada) e a estrutural”, em que a interdisciplinaridade linear ou cruzada corresponde a:

[...] uma forma elaborada de pluridisciplinaridade. As disciplinas permutam informações, não há reciprocidade nas trocas e a cooperação metodológica é praticamente nula. As disciplinas que fornecem informações a uma outra fazem-no a título de disciplinas 'auxiliares', permanecendo, relativamente a ela, numa situação de dependência ou de subordinação (CARLOS, 2007, p. 45).

E a interdisciplinaridade estrutural diz respeito a "[...] um tipo de interdisciplinaridade que não se efetua por simples adição nem tão pouco [sic] por mistura. O que há é uma combinação das disciplinas correspondendo ao estudo de novos campos de problemas" (CARLOS, 2007, p. 45).

Prosseguindo com outras interpretações sobre interdisciplinaridade, conforme o
dicionário pedagógico de Queiroz (2003, p. 154), interdisciplinaridade é '[...] termo
que traduz uma nova postura diante do saber, uma busca da unidade do
conhecimento. Pondo de lado a visão fragmentada ou dicotômica do objeto de
estudo [...]'. Nos Parâmetros Curriculares Nacionais (PCNs), a interdisciplinaridade:
[...] supõe um eixo integrador, que pode ser o objeto de conhecimento, um projeto de
investigação, um plano de intervenção. Nesse sentido, ela deve partir da
necessidade sentida pelas escolas, professores e alunos de explicar, compreender,
intervir, mudar, prever, algo que desafia uma disciplina isolada e atrai a atenção de
mais de um olhar, talvez vários (BRASIL, 2002, p. 88-89, grifo do original).

Todavia, a discussão sobre a palavra "interdisciplinar" não é estanque ou resumida apenas aos significados simplistas de algumas linguagens de dicionários, no sentido de que interdisciplinaridade é aquilo que é comum a várias disciplinas ou resultado do confronto entre elas. Por vezes, pode haver questões que não possam ser resolvidas apenas com a complementaridade da parte comum das disciplinas, isto é, com a interdisciplinaridade. "Neste caso, dever-se-ia utilizar preferencialmente a palavra 'pluridisciplinar', que seria mais justa"” (ARÉNILLA et al., 2000, p. 271). Porém, pode haver questões que extrapolam os domínios das disciplinas. Nesse caso, necessita-se de um termo que designe genericamente situações ou experiências vividas que não são comportadas por nenhuma disciplina no âmbito curricular do conhecimento, a "transdisciplinaridade". Seriam, por exemplo, "Os problemas educativos colocados [...] pelo desenvolvimento dos alunos, pelos seus comportamentos ou resultados" (ARÉNILLA et al., 2000, p. 271).

Já a multidisciplinaridade, na categoria de outro nível de conhecimento, está frequentemente presente na gestão docente, fazendo parte da estrutura tradicional curricular,

\section{POLÊM!CA $\mid$ LABORE}

Polêmica - Revista Eletrônica da Uerj - Rua São Francisco Xavier, 524, $1^{\circ}$ andar

bloco D, sl.1001 • Tels.: +55 21 2334-4088/4087 • http://www.e-publicacoes.uerj.br/index.php/polemica/index

http://www.labore.uerj.br • laboreuerj@yahoo.com.br 
tendo sido trabalhada antes mesmo da perspectiva interdisciplinar. Através da multidisciplinaridade, as disciplinas ou saberes são trabalhados de forma desconectada, a fim de alcançar objetivos específicos individualizados para cada uma das disciplinas. Nesse caso, trata-se de trabalhar ou desenvolver o ensino-aprendizagem de maneira fragmentada, sem a preocupação de perceber e refletir a integração ou cooperação existentes entre os diferentes processos de ensino-aprendizagem. Essa concepção de se trabalhar o conhecimento sob um viés fragmentado ou individualizado faz parte do ideário cartesiano de método próprio dispensado a um objeto reconhecido que abre mão das possíveis relações entre as disciplinas.

Por outro lado, a diferença entre a multidisciplinaridade e a pluridisciplinaridade ancora-se no fato de que esta, mesmo considerando haver um sistema nivelado entre as disciplinas, aceita o trabalho de disciplinas justapostas e agrupadas, possibilitando emergir relações ou interconexões comuns entre elas em um mesmo patamar hierárquico (MENEZES; SANTOS, 2002).

O pensamento sobre a interdisciplinaridade (nos moldes atuais) tem sido fértil no contexto das práticas educativas, sobretudo com o desenvolvimento científico e tecnológico, principalmente a partir das últimas décadas do século $\mathrm{XX}$, com o advento da internet e de outros meios de comunicação, embora se saiba que o trabalho intelectual com a interdisciplinaridade não seja de agora, visto que a própria convivência social exige essa demanda nas relações, seja do homem com seu próximo, seja deste com a natureza.

Na realidade atual, especificamente no âmbito educacional, há uma nova atitude ante a questão do conhecimento, a qual diz respeito à abertura à compreensão de aspectos ocultos do ato de aprender. Exige, portanto, uma profunda imersão no trabalho cotidiano nas práticas educativas, fazendo, não raro, emergir questões durante a gestão educativa em sala de aula que vão além do domínio das disciplinas, o que exige uma denominação geral de transdisciplinaridade. Essa situação está presente, por exemplo, quando se desce do palco rígido do estatuto científico aflorado e implantado pelos grandes centros que se autodenominavam de detentores e tipificadores de um conhecimento científico, departamentalizado por área e disciplinarmente distribuído segundo a hierarquização das ciências com o surgimento do Estado Moderno e principalmente com o positivismo proposto pelo francês Augusto Comte a partir da segunda metade do século XIX (XAVIER, 2014).

\section{POLÊM!CA $\mid$ LABORE}


Com efeito, a interdisciplinaridade reivindicada e fertilizada no plano do conhecimento dos dias atuais não é matéria nova. Desde a Antiguidade Clássica, sabe-se que essa era uma prática comum entre os renomados pensadores que incorporavam consigo várias áreas do conhecimento sob o signo de uma única: a filosofia.

Assim, essa perspectiva passou a tomar novos e individualizados ramos do conhecimento em decorrência do advento do Estado Moderno, mais precisamente em decorrência da vaidade de seus próprios idealizadores. A tentativa positivista comtiana de hierarquização e departamentalização do conhecimento enrijeceu e tentou emudecer as vozes da subjetividade e intersubjetividade do ser e do fazer humanos na Terra.

Certamente as categorias da subjetividade e da intersubjetividade humanas transcendem a prática da interdisciplinaridade para a prática e a práxis das trans e pluridisciplinaridades num movimento dialético e dialógico (WERNECK, 1998). Tautologicamente ao pensamento sistêmico - que crê no desenvolvimento da racionalidade científica em conjunto com a subjetividade presente no ser e nas inúmeras crenças espirituais -, as concepções inter, pluri e transdisciplinares, como níveis interativos crescentes entre as disciplinas (CARLOS, 2007), são maneiras de abordagem de diferentes temáticas pertinentes, especialmente após a segunda metade do século $\mathrm{XX}$, as quais se contrapõem ao chamado pensamento reducionistamecanicista do ideário da Revolução Científica dos séculos XVI e XVII, representado principalmente por Descartes, Bacon e Newton, que mais se aproximavam da forma multidisciplinar (ROCHA FILHO, 2007; SILVA, 2001).

O fato é que hoje, na gestão das práticas educativas em sala de aula, é possível trabalhar sob o prisma da conciliação de temas ou áreas do conhecimento, encontrando inclusive pontos convergentes. Esse é o caso de uma ciência empírico-formal e de uma ciência da hermenêutica ou normativa, como é o caso comparativo da matemática e do direito, quando buscam solucionar distintas questões com base em pontos convergentes encontrados seja no campo da realidade objetiva, seja no campo consensual das ideais (ABETTE; CABETTE, 2011).

\section{Interdisciplinaridade no contexto das Diretrizes Curriculares Nacionais}

Além de sua forte influência na legislação e nas propostas curriculares, a interdisciplinaridade ganhou força nas escolas, principalmente no discurso e na prática de professores dos diversos níveis de ensino (FAZENDA, 1994).

\section{POLÊM!CA $\mid$ LABORE}


O contexto mais intenso da abordagem sobre a interdisciplinaridade entre as variadas temáticas que envolvem as práticas educativas se dá com o estabelecimento dos Parâmetros Curriculares Nacionais (PCNs) como segmento normativo em cumprimento da vigente LDBEN (Lei n 9.394/1996). Todavia, bem antes da instituição da LDBEN de 1996, já se reivindicavam práticas interdisciplinares no âmbito educacional a partir da reformulação da LDBEN de 1971 (Lei $\mathrm{n}^{\circ}$ 5.692/1971). Mas as questões envolvendo a abordagem sobre a interdisciplinaridade nas práticas docentes/discentes contemporaneamente ecoam do velho continente ainda na década de 1960. Citando Fazenda (1994), Carlos (2007, p. 34) observa que:

[...] a interdisciplinaridade surgiu na França e na Itália em meados da década de 60, num período marcado pelos movimentos estudantis que, dentre outras coisas, reivindicavam um ensino mais sintonizado com as grandes questões de ordem social, política e econômica da época. A interdisciplinaridade teria sido uma resposta a tal reivindicação, na medida em que os grandes problemas da época não poderiam ser resolvidos por uma única disciplina ou área do saber. No final da década de 60, a interdisciplinaridade chegou ao Brasil e logo exerceu influência na elaboração da Lei de Diretrizes e Bases $n^{\circ}$ 5.692/71. Desde então, sua presença no cenário educacional brasileiro tem se intensificado e, recentemente, mais ainda, com a nova LDB n ${ }^{\circ}$ 9.394/96 e com os Parâmetros Curriculares Nacionais [...]. Além de sua forte influência na legislação e nas propostas curriculares, a interdisciplinaridade ganhou força nas escolas, principalmente no discurso e na prática de professores dos diversos níveis de ensino. Apesar disso, estudos têm revelado que a interdisciplinaridade ainda é pouco conhecida.

$\mathrm{Na}$ realidade, a temática da interdisciplinaridade, embora tenha vindo a ser influenciada pelos movimentos estudantis de boa parte da Europa ainda na década de 1960, só veio a ser debatida de forma mais fecunda e a ter sua prática docente aplicada com mais vigor no Brasil com a implantação da LDBEN de 1996. Mesmo assim, pelo menos em consonância com estudiosos já citados neste trabalho, a abordagem sobre a interdisciplinaridade e sua efetiva prática tem sido muito falada ou apregoada de forma supérflua, o que tem causado tendência para o discurso da mesmice e do descrédito, sem significativas aplicações práticas.

Nos PCNs, a parte específica com direção mais focada à efetivação da interdisciplinaridade na gestão docente é a que se refere aos temas transversais. Nessa parte exclusiva do documento, fica claro que a transversalidade e a interdisciplinaridade são interdependentes e possuem como base epistemológica a crítica da concepção de um conhecimento dado aprioristicamente com características previsíveis e imutáveis no seio social. Como abordagem concreta, os PCNs propõem trabalhar nas práticas educativas as

\section{POLÊM!CA $\mid$ LABORE}


temáticas de bloco com suas devidas derivações ou subtemáticas. Tais temáticas maiores são: ética, pluralidade cultural, meio ambiente, saúde, orientação sexual, trabalho e consumo (BRASIL, 2002).

Vale ressaltar também que os PCNs atestam que tanto a transversalidade como a interdisciplinaridade vislumbram que a compreensão do real é complexa e que as visões sobre a realidade aparente são difusas e variam de acordo com o olhar do sujeito observador, que, às vezes, pode perceber aspectos comuns entre um e outro objeto cognoscível e, às vezes, pode perceber contradições dispersas entre esses mesmos objetos, numa teia de relações que ora aproxima, ora distancia para poder aproximar novamente, num vai e vem dialético constante.

Apesar dessa base comum entre a transdisciplinaridade e a interdisciplinaridade, ambas conservam em suas bases teórico-epistemológicas reais diferenças. Nesse sentido, enquanto a primeira está relacionada com a dimensão didático-pedagógica, a segunda tem sua hermenêutica pautada na epistemologia dos objetos do conhecimento.

Na prática pedagógica, interdisciplinaridade e transversalidade alimentam-se
mutuamente, pois o tratamento das questões trazidas pelos Temas Transversais
expõe as inter-relações entre os objetos de conhecimento, de forma que não é
possível fazer um trabalho pautado na transversalidade tomando-se uma perspectiva
disciplinar rígida. A transversalidade promove uma compreensão abrangente dos
diferentes objetos de conhecimento, bem como a percepção da implicação do sujeito
de conhecimento na sua produção, superando a dicotomia entre ambos. Por essa
mesma via, a transversalidade abre espaço para a inclusão de saberes extraescolares,
possibilitando a referência a sistemas de significado construídos na realidade dos
alunos. Os Temas Transversais, portanto, dão sentido social a procedimentos e
conceitos próprios das áreas convencionais, superando assim o aprender apenas pela
necessidade escolar de 'passar de ano' (BRASIL, 2002, p. 30).

Em outras palavras, a transversalidade propõe a possibilidade de se inter-relacionar ensino-aprendizagem previamente sistematizado com a realidade experimentada, vivida e sentida nas práticas do além muro escolar. Já a interdisciplinaridade pauta-se na possibilidade de se trabalhar conteúdos teóricos na produção do conhecimento de forma inter-relacional nos diversos campos do conhecimento.

É racional relembrar que o vocábulo "interdisciplinaridade" é composto de prefixação e sufixação, em que "inter" tem significado originário de ação recíproca, comum; “disciplinar" refere-se à disciplina, ao funcionamento regular, etc.; e "dade" reporta-se à acepção de qualidade, estado ou resultado da ação. Em suma, a interdisciplinaridade está relacionada com uma nova concepção de divisão do saber, primando pela interdependência, a

\section{POLÊM!CA $\mid$ LABORE}

Polêmica - Revista Eletrônica da Uerj - Rua São Francisco Xavier, 524, $1^{\circ}$ andar

bloco D, sl.1001 • Tels.: +55 21 2334-4088/4087 • http://www.e-publicacoes.uerj.br/index.php/polemica/index

http://www.labore.uerj.br • laboreuerj@yahoo.com.br 
interação e a integração do conhecimento entre os campos do conhecimento de forma harmoniosa e significativa. E derivam-se da categoria "interdisciplinaridade” os níveis no âmbito do conhecimento: multidisciplinaridade, significando saberes fragmentados, em que existe justaposição de várias disciplinas, porém sem relação aparente entre si; pluridisciplinaridade, em que algumas disciplinas pertencentes a conteúdos afins ou a áreas se afinam e se justapõem com menor fragmentação na seara do conhecimento; e transdisciplinaridade, em que todas as disciplinas se encaixam em um sistema lógico de conhecimentos comuns com livre passagem de um campo de saber para outro, sem amarras ou limitações (ABBAGNANO, 1998).

Continuando na busca de um novo modelo produtivo de síntese no contexto teóricometodológico entre a interdisciplinaridade e seus demais níveis de conhecimento, é salutar perceber que (salvaguardando suas diferenças específicas demonstradas anteriormente) são estratégias ou recursos que direcionam para um alvo comum: integração-interação na busca de união-reunião-articulação de aberturas ou possibilidades plurais, visando à produção e à compreensão de conhecimentos em contraste com a tendência monodisciplinar. A finalidade é acoplar novas perspectivas ou novos saberes, primando por uma dialética inclusiva e não excludente do terceiro termo.

\section{Considerações finais}

A proposta conceitual e contextual presente nesta escrita não tem como vislumbre encerrar a discussão no campo didático-pedagógico. A escolha deve-se ao fato de acreditar-se que a abordagem conceitual tem a capacidade precípua de facilitar a compreensão interpretativa dos significados dos termos, que acabam, muitas vezes, por caírem na vulgaridade e converterem-se em palavras sem um significado potente e plausível de tanto serem usados inadequadamente ou menosprezados.

Desse modo, a proposta inicial da análise conceitual e contextual do vocábulo “interdisciplinaridade" na gestão das práticas educativas trouxe à tona outras possibilidades não tão somente de ensino-aprendizagem interdisciplinar, mas pluri e transdisciplinar. $\mathrm{O}$ propósito compreensivo do uso dessas categorias não paira apenas na prática educativa, mas na perspectiva reflexiva. É racional perceber também que na prática educativa, não raro, há abordagens, questões e ideias que extrapolam os domínios das disciplinas curriculares. Nesse

\section{POLÊM!CA $\mid$ LABORE}


caso, a interdisciplinaridade preestabelecida não é suficiente para comportar ou solucionar tais questões. Assim, o mais viável é recorrer ao campo da transdisciplinaridade para equacionar ou ao menos minimizar essas questões gerais na gestão das práticas educativas.

Com efeito, cada dia mais, o momento contemporâneo revela e reivindica o trabalho através do conhecimento sistêmico, sobretudo com a aplicabilidade das tecnologias da informação no âmbito científico. Mais do que nunca, a tríade ciência-tecnologiatelecomunicação aproxima e encurta caminhos antes distantes e improváveis de interconexão.

Pelo demonstrado neste sucinto artigo, pode-se perceber e refletir sobre a necessidade de a prática docente extrapolar as diretrizes e as previsões interdisciplinares, alcançando, com isso, as práticas transdisciplinares. O campo para o debate é bastante amplo e continua aberto e convidativo para estudos, pesquisas e discussões densas e férteis que contemplem a gestão docente em sala de aula e as práticas educativas como um todo.

\section{Referências}

ABBAGnANO, N. Dicionário de Filosofia. São Paulo: Martins Fontes, 1998.

ABETTE, E. L. S.; CABETTE, R. E. S. Direito e matemática: uma abordagem interdisciplinar. Jus Navigandi, Teresina, v. 16, n. 2849, 2011.

ALBARRACIN, E. S.; SILVA, S. C. R.; SCHIRLO, A. C. Interdisciplinaridade e inovação educativa: saberes e práticas. Simpósio Internacional sobre Interdisciplinaridade no Ensino, na Pesquisa e na Extensão, 2013, Florianópolis. Anais... 2013. p. 1-20.

ARÉNILLA, L. et al. Dicionário de pedagogia. Lisboa: Instituto Piaget, 2000.

BRASIL. Constituição de 1988. Constituição da República Federativa do Brasil. Diário Oficial [da] República Federativa do Brasil, Poder Executivo, Brasília, DF, 5 out. 1988.

Lei $\mathrm{n}^{\circ}$ 5.692, de 11 de agosto de 1971. Fixa Diretrizes e Bases para o Ensino de $1^{\circ}$ e $2^{\circ}$ Graus, e dá outras providências. Diário Oficial [da] República Federativa do Brasil, Poder Executivo, Brasília, DF, 12 ago. 1971 .

. Lei n ${ }^{\circ}$ 9.394, de 20 de dezembro de 1996. Estabelece as Diretrizes e Bases da Educação Nacional. Diário Oficial [da] República Federativa do Brasil, Poder Executivo, Brasília, DF, 21 dez. 1996.

Ministério da Educação. Secretaria de Educação Média e Tecnológica. Parâmetros Curriculares Nacionais: ensino médio. Brasília, DF: Ministério da Educação, 2002.

CARLOS, J. G. Interdisciplinaridade no ensino médio: desafios e potencialidades. 2007. 172 f. Dissertação (Mestrado profissionalizante em Ensino de Ciências) - Programa de Pós-Graduação em Ensino de Ciências, Universidade de Brasília, Brasília, DF, 2007.

CHIZZOTTI, A. Pesquisa qualitativa em ciências humanas e sociais. 4. ed. Petrópolis: Vozes, 2011.

\section{POLÊM!CA $\mid$ LABORË}


FAZENDA, I. C. A. Interdisciplinaridade: história, teoria e pesquisa. 4. ed. Campinas: Papirus, 1994.

(Org.). Metodologia da pesquisa educacional. São Paulo: Cortez, 2010.

(Org.). Práticas interdisciplinares na escola. São Paulo: Cortez, 2011.

Org.). O que é interdisciplinaridade? São Paulo: Cortez, 2008.

FERREIRA, G. O ciclo didático e as etnociências como proposta de contextualização do ensino de ciências na educação básica. 2014. 171 f. Tese (Doutorado em Educação em Ciências e Matemática) - Programa de Pós-Graduação em Educação em Ciências e Matemática, Universidade Federal de Mato Grosso, Universidade Federal do Pará, Universidade Estadual do Amazonas, Cuiabá, 2014.

GAMITO, J. A. S. Filosofia da ciência. Texto-base para as aulas de Fundamentos Psicológicos da Educação no curso de Pós-Graduação de Docência do Ensino Superior do Instituto de Ciências Humanas João Paulo II (IJOPA) / Faculdade Católica de Anápolis, Cachoeiro de Itapemirim (ES) e Campos (RJ), 2013. Disponível em: <http://docenciadefilosofia.blogspot.com.br/>. Acesso em: 20 out. 2014.

JAPIASSU, H. Interdisciplinaridade e patologia do saber. Rio de Janeiro: Imago, 1976.

LÉVY, P. Cibercultura. São Paulo: 34, 1999.

MENEZES, E. T.; SANTOS, T. H. "Multidisciplinaridade" (verbete). Dicionário interativo da Educação Brasileira: Educa Brasil. São Paulo: Midiamix, 2002.

MORAIS, R. Filosofia da ciência e da tecnologia. 5. ed. São Paulo: Papirus, 1988.

MORIN, E. A cabeça bem feita: repensar a reforma, reformar o pensamento. 15. ed. Rio de Janeiro: Bertrand Brasil, 2008.

Introdução ao pensamento complexo. 3. ed. Porto Alegre: Sulina, 2007.

PANOFF, M.; PERRIN, M. Dicionário de etnologia. Lisboa: 70, 1973.

ROCHA FILHO, J. B. Transdisciplinaridade: a natureza íntima da educação científica. Porto Alegre: PUCRS, 2007.

SANTOS, B. S.; MENESES, M. P. (Org.). Epistemologias do Sul. São Paulo: Cortez, 2010.

SILVA, E. M. P. E. Os caminhos da transdisciplinaridade. In: DOMINGUES, I. (Org.). Conhecimento e transdisciplinaridade. Belo Horizonte: UFMG/IEAT, 2001. p. 35-43.

SOUZA, F. C. S.; MOREIRA, K. A.; PEREIRA, M. R. A interdisciplinaridade na prática dos educadores sociais do Programa de Criança Petrobras. Polêm!ca, Rio de Janeiro, v. 17, n. 2, p. 54-67, 2017.

TRUEBA, C. C. Ciencia y etnociencia. Revista Ciencias, n. 66, p. 106-117, 2002.

WERNECK, H. Ensinamos demais: aprendemos de menos. 14. ed. São Paulo: Vozes, 1998.

XAVIER, A. R. Joana Paula de Morais: história, memórias e trajetórias educativas (1900-1963). 2014. 411f. Tese (Doutorado em Educação) - Programa de Pós-Graduação em Educação, Universidade Federal do Ceará, Fortaleza, 2014.

Recebido em: 28/04/2017.

Aceito em: 30/01/2018.

\section{POLÊM!CA $\mid$ LABORE}

Polêmica - Revista Eletrônica da Uerj - Rua São Francisco Xavier, 524, $1^{\circ}$ andar

bloco D, sl.1001 • Tels.: +55 21 2334-4088/4087• http://www.e-publicacoes.uerj.br/index.php/polemica/index

http://www.labore.uerj.br • laboreuerj@yahoo.com.br 